\title{
Preanesthetic severe postural hypotension following 5-aminolevulinic acid pretreatment in patients for photodynamic diagnosis-assisted urological surgery
}

\author{
Tohru Shiratori $^{1 *}$ D, Kunihisa Hotta ${ }^{2}$, Masaaki Satoh ${ }^{3}$, Chiaki Kiuchi ${ }^{1}$, Noriyuki Ogawa ${ }^{3}$ and Takayuki Kamigaito ${ }^{3}$
}

\begin{abstract}
Background: 5-Aminolevulinic acid (5-ALA) is utilized for photodynamic diagnosis-assisted (PDD) surgery. However, it has been associated with vasodilation, hence, occasional hypotension.

Case presentation: We encountered two patients who had severe postural hypotension following 5-ALA pretreatment prior to an operation. They were scheduled for urological PDD surgery, but upon standing to walk to the operation room, they felt sick because of severe hypotension. One of them underwent the surgery after recovery, but the other surgery was canceled due to a prolonged hypotension that lasted for more than a day.

Conclusions: Severe postural hypotension may develop as a result of the high concentration of porphyrin precursors, which may affect the nervous system. Severe postural hypotension may be due to 5-ALA-induced autonomic dysfunction as well as vasodilative action of 5-ALA. These observations suggest that in addition to the careful monitoring of patients' vital signs, standing should be avoided following 5-ALA pretreatment.
\end{abstract}

Keywords: 5-Aminolevulinic acid, Photodynamic diagnosis, Fluorescence, Anesthesia, Hypotension, Postural hypotension, Vasodilation, Porphyrin, Autonomic neuropathy, Bladder tumor

\section{Background}

5-Aminolevulinic acid (5-ALA) is a precursor of protoporphyrin IX (PpIX), which has high tumor selectivity and photoactivity, leading to more accurate visualization of cancer tissues. 5-ALA is utilized for photodynamic diagnosis-assisted (PDD) glioma or bladder tumor surgery, and it is orally administered $3 \mathrm{~h}$ before the surgery [1-3]. Although hypotension is among the adverse events associated with 5-ALA, it has not been well recognized as serious [1-3]. This may partly explain why the characteristics, clinical course, and mechanism of 5ALA-induced hypotension have not been fully elucidated. A recent case report described the anesthetic course of 5-ALA-induced severe hypotension that occurred immediately after the induction of general

\footnotetext{
*Correspondence: ts_62475@inahp.jp

'Department of Anesthesiology, Ina Central Hospital, 1313-1 Koshiroukubo,

Ina, Nagano 396-8555, Japan

Full list of author information is available at the end of the article
}

anesthesia [4]. Here, we report two cases of severe postural hypotension following 5-ALA pretreatment for transurethral resection of bladder tumor (TURBT).

\section{Case presentation \\ Case 1}

A 75-year-old man (height $165 \mathrm{~cm}$, weight $63 \mathrm{~kg}$ ) was scheduled to undergo his third TURBT. For prostatic hyperplasia, he was prescribed $5 \alpha$-reductase inhibitor. Preoperative examinations were within the normal ranges. Systolic blood pressure (S-BP) was about $140 \mathrm{mmHg}$ at home. On the patient's request, general anesthesia was planned. On the day of the operation, the BP was $139 / 82 \mathrm{mmHg}$. A nitroglycerin transdermal patch (nitroglycerin $25 \mathrm{mg}$ ) was used at the start of preoperative crystalloid infusion $(100 \mathrm{~mL} / \mathrm{hr})$ as a routine medication against perioperative myocardial ischemia. For the first time in his life, the patient took a 5-ALA (1.5 g) solution $3 \mathrm{~h}$ before TURBT but felt sick afterwards. About $2 \mathrm{~h}$ later, the patient walked to the lavatory, but upon returning, 
he could not sit by himself and had a severe staggered feeling and nausea. Although his S-BP was $42 \mathrm{mmHg}$, he was fully conscious. The patient had cold sweats and a pulse rate (PR) of $70-80 \mathrm{bpm}$, but other skin symptoms were absent. The blood glucose level was $146 \mathrm{mg} / \mathrm{dL}$. Placing the patient in the Trendelenburg position with fluid resuscitation brought recovery from the shock. Before entering the operating room, the BP and PR were $96 / 55 \mathrm{mmHg}$ and $67 \mathrm{bpm}$, respectively. General anesthesia was induced with atropine $(0.5 \mathrm{mg})$, propofol $(80 \mathrm{mg})$, and rocuronium $(30 \mathrm{mg})$. Anesthesia was maintained with sevoflurane (1.0-1.5\%) and remifentanil $(100-300 \mu \mathrm{g} / \mathrm{h})$. Although ephedrine (total dose $15 \mathrm{mg}$ ) and phenylephrine (total dose $0.2 \mathrm{mg}$ ) were necessary to maintain S-BP above $80 \mathrm{mmHg}$, abnormal hypotension did not develop during the PDD surgery. The operation was completed without any incident, and the postoperative course was uneventful. However, the pathology report suggested the need for a future PDD surgery. With the nitroglycerin patch attached, the hypotension seemed non-ischemic. Although the nitroglycerin patch could have affected the preoperative BP, it was difficult to conclude that the patch caused the severe hypotension.

\section{Case 2}

A 68-year-old man $(170 \mathrm{~cm}, 70 \mathrm{~kg})$ was planned for his first elective PDD TURBT under spinal anesthesia. The patient was medicated with losartan $(25 \mathrm{mg} /$ day $)$ for hypertension and tamsulosin $(0.2 \mathrm{mg} /$ day $)$ for dysuria. Preoperative examinations were within the normal ranges. On the day of the operation, the $\mathrm{BP}$ and $\mathrm{PR}$ were $126 / 81 \mathrm{mmHg}$ and $71 \mathrm{bpm}$ in the early morning, respectively. Daily medications were orally administered. Subsequently, crystalloid infusion was started. About $3 \mathrm{~h}$ before the PDD TURBT, the patient took a 5-ALA (1.5 g) solution. Thirty minutes before entering the operation room, the BP and PR were $96 / 57 \mathrm{mmHg}$ and $80 \mathrm{bpm}$, respectively. When the patient stood up and headed to the operation room, he felt sick. The S-BP was $42 \mathrm{mmHg}$ at that time. After $20 \mathrm{~min}$, the vital signs were $76 / 44 \mathrm{mmHg}$ and $68 \mathrm{bpm}$, respectively. He complained of dizziness with cold sweat and no rash. Fluid resuscitation with the Trendelenburg position was initiated. The operation was canceled due to sustained hypotension, and continuous dopamine infusion $(0.3 \%$ solution; $3 \mathrm{~mL} / \mathrm{hr}$ ) was started. About $16 \mathrm{~h}$ after the 5-ALA pretreatment, the vital signs were $67 / 32 \mathrm{mmHg}$ and $78 \mathrm{bpm}$, respectively. Continuous dopamine infusion was necessary until the next day. No reason was found for the hypotension except the 5-ALA pretreatment.

\section{Discussion}

The clinical courses of the two patients suggest some important findings following 5-ALA pretreatment: first, severe postural hypotension followed 5-ALA pretreatment; second, severe postural hypotension occurred about $3 \mathrm{~h}$ after 5-ALA pretreatment; and third, the hypotension was severe in the abrupt onset and duration.

The clinical situations of the two patients may indicate a causal relationship between severe postural hypotension and exposure to 5-ALA, this being the common clinical factor between them. The possible causes of the postural hypotension observed in the two patients could be strong vasodilation and autonomic disorder. 5-ALA may induce vasodilative action [5]; however, it is debatable whether severe hypotension is ascribed only to vasodilative action because 5-ALA does not always induce severe BP decrease and its dose-response relationship is unclear. According to previous researches, there have been some concerns about the relationship between 5-ALA-induced hypotension and antihypertensive therapy [6, 7]. Although preanesthetic antihypertensive may be a factor spurring hypotension, it is uncertain whether the severe postural hypotension was only due to 5-ALA pretreatment in combination with the antihypertensive because 5-ALA-pretreated patients medicated together with antihypertensive have not always experienced preanesthetic severe hypotension in clinical practice. Previous trials contain no information on how patients moved to the operation room. In neurosurgical trials, patients with high-grade glioma are considered to have been laid on the bed before an operation. Postural hypotension may not have developed in neurosurgical trials because such patients hardly have the need to walk to the operation room and are usually transferred on the bed. While we have hypothesized that autonomic reflex dysfunction or strong vasodilation beyond autonomic reflex may be responsible for the severe hypotension observed in our patients, the true mechanism is not known.

The onset time of severe hypotension in our cases was approximately $3 \mathrm{~h}$ after 5-ALA pretreatment, similar to a recent report [4] and seems to coincide with an increase in plasma PpIX concentration. PpIX concentration slopes upward an hour after 5-ALA pretreatment, and the 3 -h concentration reaches about 3 times as high in an hour [5], indicating that substantial exogenous 5-ALA yields high concentrations of porphyrin precursors, similar to porphyria in terms of high porphyrins. While it was concluded that 5-ALA does not induce porphyria $[8,9]$, there is a report presenting a patient with 5-ALA-induced acute neuropathy similar to porphyria who experienced recurrent postural hypotension [10]. Postural hypotension is among the signs of porphyria autonomic neuropathy, and ample 5-ALA is supposed to have direct neurotoxicity [11-13]. Considering this fact, it is possible 
that autonomic dysfunction develops around $3 \mathrm{~h}$ after 5-ALA pretreatment when the concentration of porphyrin precursors becomes extremely high. Given that substantial exogenous 5-ALA can neurogenically affect $\mathrm{BP}$ regulation, consultation from a neurologist may be needed.

The abrupt onset of profound hypotension and duration of BP decrease was serious; therefore, anaphylactic shock should be differentiated. 5-ALA can induce hypersensitivity. Two previous clinical studies have each listed a case with 5-ALA-related rash [1] and urticaria [3], and anaphylactic shock occurred in a patient with intravesical 5ALA-derivative [14]. Thorough inspections for hypersensitivity may be required in severe cases [4]. According to a recent report, 5-ALA-induced hypotension may possibly be vasoactive-refractory [4]. While severe hypotension improved in the first case, the second case suffered prolonged hypotension that continued by the next day despite continuous dopamine infusion. Although it is not fully elucidated what classes of antihypertensive drugs significantly contribute to 5-ALA-induced hypotension, preoperative administration of angiotensin-receptor-blocker is known to be associated with an increased incidence of intraoperative hypotension $[15,16]$. Losartan was administered in the second case, taking into account its advantages and disadvantages, but it may have been attributed to the severity and prolonged duration of 5-ALA-induced hypotension. Given that the effects of 5-ALA are strong and long-lasting, adequate vasoactives and careful monitoring over a day will be necessary when dealing with 5ALA-induced hypotension.

When treating patients with 5-ALA pretreatment, there are some important insights elicited from the present cases. Standing should be avoided, and it is beneficial not to take vasodilatives preoperatively together with 5-ALA. Checking for vital signs is needed around $3 \mathrm{~h}$ after 5-ALA pretreatment. Preparation for prolonged hypotension may be required. As for 5ALA indication, it is necessary to elucidate whether a history of 5-ALA-induced hypotension is a risk factor for the next 5-ALA pretreatment, because a previous study described recurrent symptomatic hypotension in patients with similar hypotensive histories [17]. However, the description lacks sufficient clinical details to draw generalizations.

In conclusion, we admitted two patients with severe postural hypotension following 5-ALA pretreatment. One patient managed to undergo PDD TURBT with general anesthesia after recovering from the hypotension, but the other could not undergo the procedure due to prolonged hypotension. Since 5-ALA may affect the nervous system, the severe hypotension observed in our patients may be attributable to the effects of 5-ALA-induced autonomic dysfunction. As such, careful monitoring of the vital signs during perioperative period is required after 5-ALA pretreatment and patients so treated should avoid standing. The relationship between 5-ALA and porphyrin metabolism may be investigated to unravel possible mechanisms for severe hypotension.

Abbreviations

5-ALA: 5-Aminolevulinic acid; PDD: Photodynamic diagnosis-assisted; PpIX : Protoporphyrin IX; PR: Pulse rate; S-BP: Systolic blood pressure;

TURBT: Transurethral resection of bladder tumor

\section{Acknowledgements}

Not applicable.

Authors' contributions

$\mathrm{TS}, \mathrm{KH}$, and MS wrote the manuscript. $\mathrm{KH}$ and MS revised the manuscript. $\mathrm{KH}$ supervised this work. TS prepared the manuscript files in consultation with CK, NO, and TK. All authors reviewed and approved the final manuscript for submission.

\section{Funding}

The authors declare that they have no founding.

Availability of data and materials

Not applicable.

Ethics approval and consent to participate

Not applicable.

\section{Consent for publication}

Written informed consent was obtained from patients for publication of this case report.

\section{Competing interests}

The authors declare that they have no competing interests.

\section{Author details}

'Department of Anesthesiology, Ina Central Hospital, 1313-1 Koshiroukubo, Ina, Nagano 396-8555, Japan. ${ }^{2}$ Department of Anesthesiology and Critical Care Medicine, Jichi Medical University, 3311-1 Yakushiji, Shimotsuke, Tochigi 329-0498, Japan. ${ }^{3}$ Department of Urology, Ina Central Hospital, 1313-1 Koshiroukubo, Ina, Nagano 396-8555, Japan.

Received: 4 October 2019 Accepted: 23 October 2019

Published online: 09 November 2019

\section{References}

1. Lau D, Hervey-Jumper SL, Chang S, Molinaro AM, McDermott MW, Phillips $J$ J, et al. A prospective phase II clinical trial of 5-aminolevulinic acid to assess the correlation of intraoperative fluorescence intensity and degree of histologic cellularity during resection of high-grade gliomas. J Neurosurg. 2016:124:1300-9.

2. Inoue K. 5-Aminolevulinic acid-mediated photodynamic therapy for bladder cancer. Int J Urol. 2017;24:97-101.

3. Nakai $Y$, Inoue $K$, Tsuzuki $T$, Shimamoto $T$, Shuin $T$, Nagao $K$, et al. Oral 5-aminolevulinic acid-mediated photodynamic diagnosis using fluorescence cystoscopy for non-muscle-invasive bladder cancer: a multicenter phase III study. Int J Urol. 2018;25:723-9 https://doi.org/ 10.1111/iju.13718

4. Yatabe T, Shigematsu-Locatelli M, Fukuhara H, Karashima T, Inoue K, Yokoyama M. 5-Aminolevulinic acid-induced severe hypotension during transurethral resection of a bladder tumor: a case report. JA Clin Rep. 2019:5.

5. Herman MA, Webber J, Fromm D, Kessel D. Hemodynamic effects of 5-aminolevulinic acid in humans. J Photochem Photobiol B Biol. 1998; 43:61-5.

6. Chung IWH, Eljamel S. Risk factors for developing oral 5-aminolevulinic acid-induced side effects in patients undergoing fluorescence guided resection. Photodiagn Photodyn Ther. 2013;10:362-7.

7. Nohara T, Kato Y, Nakano T, Nakagawa T, Iwamoto H, Yaegashi $H$, et al. Intraoperative hypotension caused by oral administration of 5-aminolevulinic 
acid for photodynamic diagnosis in patients with bladder cancer. Int J Urol. 2019;26(11):1064-8.

8. Mustajoki P, Timonen K, Gorchein A, Seppäläinen AM, Matikainen E, Tenhunen R. Sustained high plasma 5-aminolaevulinic acid concentration in a volunteer: no porphyric symptoms. Eur J Clin Investig. 1992;22:407-11.

9. Webber J, Kessel D, Fromm D. Side effects and photosensitization of human tissues after aminolevulinic acid. J Surg Res. 1997;68:31-7.

10. Sylantiev C, Schoenfeld N, Mamet R, Groozman GB, Drory VE. Acute neuropathy mimicking porphyria induced by aminolevulinic acid during photodynamic therapy. Muscle Nerve. 2005;31:390-3.

11. Albers JW, Fink JK. Porphyric neuropathy. Muscle Nerve. 2004;30:410-22.

12. Peter Bosch E, Smith BE. Disorders of peripheral nerves. In: Bradley WG, Daroff RB, Fenichel GM, Jankovic J, editors. Neurology in clinical practice 4th ed. Philadelphia: Elsevier; 2004. p. 2331-3.

13. Katirji B, Koontz D. Disorders of peripheral nerves. In: Daroff RB, Fenichel GM, Jankovic J, Mazziotta JC, editors. Bradley's neurology in clinical practice. 6th ed. Philadelphia: Elsevier; 2012. p. 1950-1.

14. Colapaoli L, Thorsen J, Nopp A, Guttormsen AB. A case of anaphylactic shock possibly caused by intravesical Hexvix. Acta Anaesthesiol Scand. 2006; 50:1165-7.

15. Lee SM, Takemoto S, Wallace AW. Association between withholding angiotensin receptor blockers in the early postoperative period and 30-day mortality: a cohort study of the veterans affairs healthcare system. Anesthesiology. 2015;123:288-306.

16. Hollmann C, Fernandes NL, Biccard BM. A systematic review of outcomes associated with withholding or continuing angiotensin-converting enzyme inhibitors and angiotensin receptor blockers before noncardiac surgery. Anesth Analg. 2018;127:678-87.

17. Bondad J, Aboumarzouk OM, Moseley H, Kata SG. Oral 5-aminolevulinic acid induced photodynamic diagnostic ureterorenoscopy--does the blood pressure require monitoring? Photodiagn Photodyn Ther. 2013;10:39-41.

\section{Publisher's Note}

Springer Nature remains neutral with regard to jurisdictional claims in published maps and institutional affiliations.

\section{Submit your manuscript to a SpringerOpen ${ }^{\circ}$ journal and benefit from:}

- Convenient online submission

- Rigorous peer review

- Open access: articles freely available online

- High visibility within the field

- Retaining the copyright to your article 